Journal of Education and Vocational Research

Vol. 2, No. 4, pp. 138-142, Oct 2011 (ISSN 2221-2590)

\title{
Scientific Output: Evidence from Iran and the Middle East
}

\author{
Ahmad Jafari Samimi*, Hoda Rezaei Roshan \\ Islamic Azad University, Firoozkooh, Iran \\ *jafarisa@yahoo.com
}

\begin{abstract}
Scientific output is one of the most important determinants of economic development in every country. The process of economic growth and social development is entirely related to the count of scientific output in different countries. The purpose of the present paper is to examine the scientific output in Iran and compare it to selected Middle Eastern countries. Our findings indicate that not only scientific output in Iran increased during 1996-2009 but this country presented the fastest-growing rate in the world in the last 5 years of this period. The best performance of Iran has been in the field of engineering and ranked first in Middle East. Also, in other fields this country performance has been by far better than the average of the region. The interesting point regarding the Iranian performance is that at the beginning of this period the scientific output of Iran has been much less than countries such as Egypt and even Saudi Arabia in the region. Iran ranked $22^{\text {nd in }} 2009$ in the World and if maintains its current trend it will soon be among the first 10 countries in the World.
\end{abstract}

Keywords: Scientific output, economic development, Middle East, Publication, Iran

\section{Introduction}

Innovation in economics cause more production, more consumer satisfaction, better qualification in production, new management methods, better use of resources and assets and So on. The important factors that can invent and introduce the innovation are encouraging the talents and creative powers, and on the other hand have the enormous investment on these creative powers. Scientific output like publishing the articles can be innovation (Zolfi, 2007). In developed countries, scientific and applied researching is an emergency investment for long-term comfort. They know very important the universities for training the scientific and technical talents, and know the learning of the university students' permanently (Bilsel \& Oral, 1995). If the countries are not able to absorb the knowledge and cannot use that, they will miss the influence of its positive. For using from this benefit, the existence of centers and organizations is necessary for being able to absorb the knowledge and technology (Wagner et al., 2001).

Scientific Output of selected countries in Middle East: Poverty and dependence will solve just by making able the countries in science and knowledge (king, 2004). Therefore, at this present paper, for measuring the quantity of the science output in countries, we use the number of the published articles (Hugo \& Francisco, 2007). Of course, published articles in the press cannot be science output, in fact, the press should have the international writing board, publish regularly, and it should be cited to the international committee. The quality and quantity assessment of articles and the press, and comparing with different countries get from the available information in ISI (Institute for Scientific Information) (Moin et al., 2007). On the other hand, the unbalanced distribution of scientific activity generates serious problems not only for the scientific community in the developing countries, but also for development itself. Nevertheless, the relative increase in the number of publications, demonstrate that many developing countries are heading in the right direction (Schnitzer \& Holmgren, 2004). As it clear, Middle East countries are developing countries, so paying attention to these countries and knowing the position of scientific output of them can be considerable.

This section deals with the published outputs of the selected Middle East countries between 1996 and 2009 that has shown in the table (1). As it consider, the scientific output during mentioned years indicate Iran's scientific progress; the number of publication is swelled from 806 in 1996 to 21,673 in 2009. Iran's scientists published the scientific output at different fields of nature, medicine, mathematics, chemistry and so on that has made Iran's scientific progress considerably suitable. The scientific output in Iran with 806 topics has been much less than some of countries in the region such as Saudi Arabia, Egypt and Israel; Israel's scientific output with 10,059 has been much more than the others in 1996. The scientific output in Iran increased to 
2,011 topics in 2001 that is more than the scientific output in Saudi Arabia. In 2003, the scientific researches in Iran have been published more than Egypt's scientific output. Perhaps the most revealing is relate to the output of science in Israel that overall publication during the period 1996-2007 has demonstrate the higher scientific output in comparison with Saudi Arabia, Egypt and Iran but in the years 2008 and 2009 Iran contributed the top research in the selected countries.

Table 1: Scientific Output of Selected Countries 1996-2009

\begin{tabular}{lllll}
\hline Year & Saudi Arabia & Egypt & Iran & Israel \\
\hline 1996 & 1,941 & 2,732 & 806 & 10,059 \\
1997 & 1,918 & 2,738 & 1,022 & 10,415 \\
1998 & 1,879 & 2,744 & 1,121 & 10,199 \\
1999 & 1,776 & 2,660 & 1,346 & 10,338 \\
2000 & 1,831 & 2,851 & 1,663 & 10,842 \\
2001 & 1,696 & 3,070 & 2,011 & 10,698 \\
2002 & 1,816 & 3,246 & 2,767 & 11,009 \\
2003 & 2,122 & 3,819 & 3,963 & 12,586 \\
2004 & 2,105 & 4,055 & 5,165 & 12,892 \\
2005 & 2,160 & 4,207 & 7,376 & 13,251 \\
2006 & 2,340 & 4,712 & 10,537 & 14,121 \\
2007 & 2,539 & 5,307 & 14,017 & 14,409 \\
2008 & 2,886 & 5,894 & 17,856 & 14,658 \\
2009 & 3,765 & 7,411 & 21,673 & 14,544 \\
\hline
\end{tabular}

Source: Scopus 2011

In 2001, Iran with its population in comparison with developed countries such as United States, Western European and Japan produce 100 times less and it is because of two reasons: 1. The GNP per capita in Iran is about 10 times less than the GNP per capita of developed countries 2. Spending on research and scientific output is about 10 times less than the mentioned developed countries (Jafari, 2006). However, according to a new report by the UK's Royal Society, currently Iran invests around 0.59 percent of its GDP on research and development (the EU invests around 1.8 percent), but has plans to increase its investment to 4 percent by 2030. The report also found that Turkey's research output increased by 43 percent between 1995 and 2007.

Measured by the number of peer-reviewed papers published in international journals, Iran's scientific output is the fastest-growing in the world. The number of scientific articles (in the table and figure (1)), illustrate that Iran's scientific progress is swelled very fast in the last five years of this period. The curve in Turkey and Iran is obviously pointing upwards but the situation in Egypt, Saudi Arabia and Jordan is definitely different.

Figure 1: Annual Research Publication Output of the five most Prolific Countries in Middle East for 2000-2009

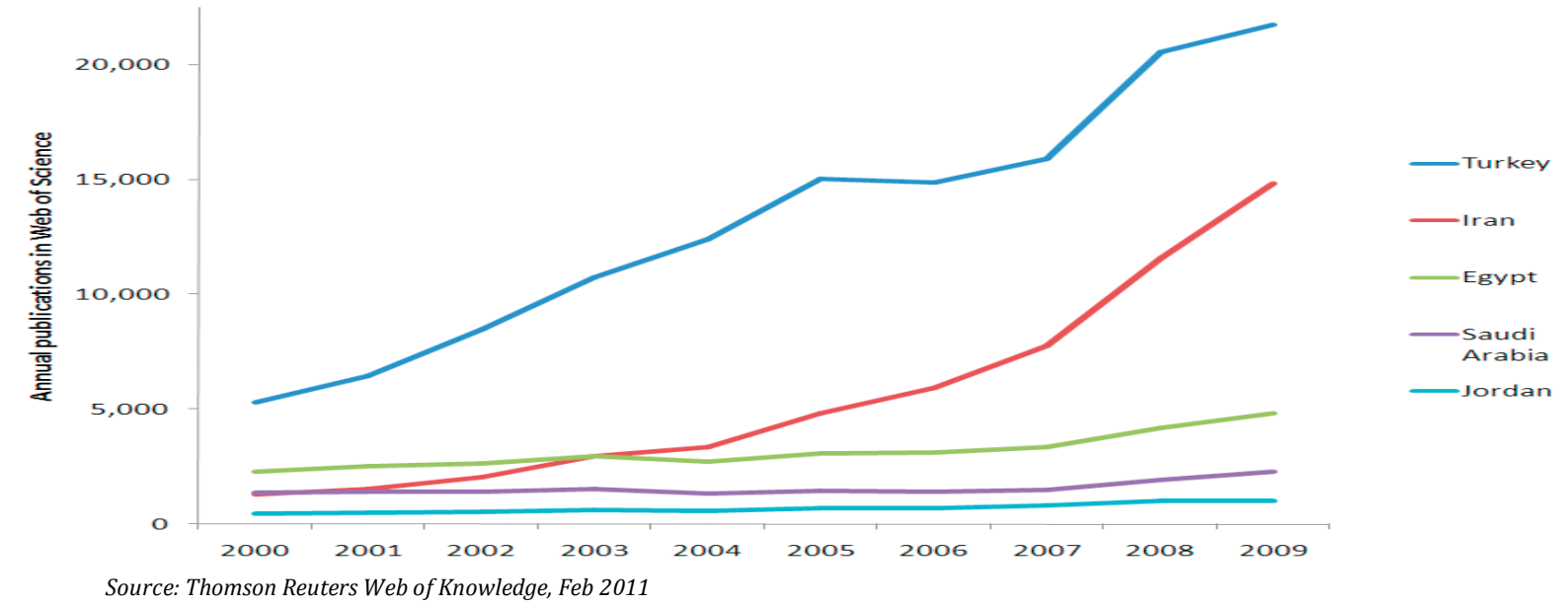


Furthermore, Iran ranked second in scientific output among whole Middle East countries and also ranked $22^{\text {nd }}$ in the world in 2009 and ranked 32nd among the countries in the world in 1996-2009. Iran has an important role in scientific output about the global divide.

The scientific output rank by global share at different fields: The gap of scientific output between the most developing and developed countries have remained enormous (Dickson, 2004). Economics development needs to direct the employment in the Knowledge generation. Even the least development in hygiene, clean water and hygienic measures, food and transportation need to the abilities in engineering, medicine, business, economic and social sciences (King, 2004). So comparing the different fields is necessary in the countries.

Table 2: Fields of Research Ranked by Global Share for 2005-2009 held by the Group of 14 Nations in Middle East

\begin{tabular}{|c|c|c|c|c|}
\hline \multicolumn{2}{|c|}{ 2000-2004 } & \multirow[b]{2}{*}{ Field } & \multicolumn{2}{|c|}{ 2005-2009 } \\
\hline $\begin{array}{l}\text { Count of } \\
\text { papers }\end{array}$ & $\begin{array}{l}\text { Share (\%) } \\
\text { of world }\end{array}$ & & $\begin{array}{l}\text { Count of } \\
\text { papers }\end{array}$ & $\begin{array}{l}\text { Share }(\%) \\
\text { of world }\end{array}$ \\
\hline 10,811 & 3.46 & Engineering & 23,712 & 5.41 \\
\hline 2,389 & 3.20 & Agricultural Sciences & 5,756 & 5.13 \\
\hline 23,977 & 2.81 & Clinical Medicine & 47,201 & 4.37 \\
\hline 13,288 & 2.70 & Chemistry & 25,200 & 4.07 \\
\hline 4,132 & 2.31 & Materials Science & 9,651 & 3.90 \\
\hline 5,184 & 2.26 & Plant \& Animal Science & 11,120 & 3.83 \\
\hline 2,472 & 3.37 & $\begin{array}{c}\text { Pharmacology \& } \\
\text { Toxicology }\end{array}$ & 3,591 & 3.62 \\
\hline 2,010 & 1.98 & Mathematics & 4,986 & 3.56 \\
\hline 2,191 & 2.15 & Environment/Ecology & 4,676 & 3.24 \\
\hline 1,653 & 1.61 & Computer Science & 4,063 & 2.90 \\
\hline 2,119 & 1.89 & Geosciences & 3,967 & 2.67 \\
\hline 6,171 & 1.56 & Physics & 11,852 & 2.40 \\
\hline 765 & 1.12 & Microbiology & 1,928 & 2.20 \\
\hline 3,055 & 1.20 & Biology \& Biochemistry & 5,869 & 2.07 \\
\hline 1,408 & 1.07 & $\begin{array}{c}\text { Neuroscience \& } \\
\text { Behavior }\end{array}$ & 3,046 & 1.97 \\
\hline 1,088 & 0.70 & Social Sciences & 4,399 & 1.93 \\
\hline
\end{tabular}

Source: Thomson Reuters Web of Knowledge, Feb 2011

This section deals with the published output of some fields such as medicine, engineering, chemistry, computer science, physics, and social sciences and so on in Middle East and the share of them in the world. Table (2) illustrates the ranking of the fields by world share. As it consider, the focus on this table is on world share, in fact the counts of papers do not be interpreted, in fact interpreting the size of scientific fields is more important. The published counts indicate the number of medicine publications rose from 23, 977 in 20002004 to 47,201 in 2005-2009 and ranked higher than the other fields, but its world share is ranked third. Engineering's publication output actually is not as well as medicine field but its world share ranked this field first. The world share at chemistry field in Middle East during the period 2005-2009 is 4.07 percent and the world share in engineering, agricultural sciences and clinical medicine fall well above this level. The less emphasize on scientific output is related to social sciences. The world share in social sciences grew at 0.70 percent in 2000-2004 to 1.93 percent in 2005-2009; as well, most other fields' share is better than this field. Furthermore, the publications in humanities sciences are not as well as the other fields; however, among the humanities sciences, the social sciences are better than the others (Jafari, 2007). Throughout this period, the overall global share of research and the count of papers rose from the years 2000-2004 to 2005-2009 as well

Examining the position of the different fields in Iran in comparison with some Middle East countries: Kofi Annan states and emphasizes that the unbalance distribution on scientific activity not only make problem for scientific society in developing countries but also interfere with developed countries too. His 
statement examined by several scientists in developed and developing countries. For instance, the estimates indicate that in 1997, developed countries use 84 percent of the world investment in their research, 72 percent for the researchers and so about 88 percent of the whole scientific and technical publications make for themselves by Science Citation Index (Segal, 1996). In addition, the important point is that the wealthy countries can research more and so the citations index will increase. But if we pay attention to the GDP per capita in many countries- for example the oil producer countries- the GDP of these countries are high but the scientific output is not enough ( Purkayatha, 2004).

At this part of paper, we examine some fields in Iran, Turkey, Egypt, and Saudi Arabia in 2009. The interesting point is related to differences in fields' distribution among religion. Turkey pattern indicates a strong emphasis on agriculture, medicine and less emphasis on neurosciences; Iran has different patterns: more emphasis on engineering and chemistry and much less emphasis on social sciences; Egypt has relatively greater emphasis on pharmacy, material sciences, and chemistry, and less emphasis on mathematics; publishing pattern in Saudi Arabia show a heavy emphasis on mathematics and engineering and a very low emphasis on microbiology.

Table 3: Global share of research output for four countries, analyzing the fields in which they are individually best represented (2009)

\begin{tabular}{|c|c|c|c|c|c|c|c|}
\hline \multicolumn{2}{|c|}{ Turkey } & \multicolumn{2}{|c|}{ Iran } & \multicolumn{2}{|c|}{ Egypt } & \multicolumn{2}{|c|}{ Saudi Arabia } \\
\hline Field & Percent & Field & Percent & Field & Percent & Field & Percent \\
\hline Agriculture & 2.87 & Engineering & 1.71 & Pharmacy & 0.71 & Mathematics & 0.32 \\
\hline Medicine & 2.84 & Chemistry & 1.68 & $\begin{array}{l}\text { Materials } \\
\text { Sciences }\end{array}$ & 0.66 & Engineering & 0.31 \\
\hline Engineering & 2.22 & $\begin{array}{l}\text { Materials } \\
\text { Sciences }\end{array}$ & 1.19 & Chemistry & 0.64 & Medicine & 0.26 \\
\hline $\begin{array}{l}\text { Plant \& Animal } \\
\text { Sciences }\end{array}$ & 2.17 & Agriculture & 1.19 & Engineering & 0.57 & Pharmacy & 0.22 \\
\hline Environment & 1.82 & Mathematics & 1.16 & Agriculture & 0.48 & $\begin{array}{l}\text { Materials } \\
\text { Sciences }\end{array}$ & 0.19 \\
\hline $\begin{array}{l}\text { Materials } \\
\text { Sciences }\end{array}$ & 1.67 & Pharmacy & 1.05 & Physics & 0.40 & Geosciences & 0.16 \\
\hline Chemistry & 1.34 & $\begin{array}{c}\text { Plant \& } \\
\text { Animal } \\
\text { Sciences }\end{array}$ & 0.93 & Microbiology & 0.35 & Chemistry & 0.15 \\
\hline Mathematics & 1.30 & $\begin{array}{l}\text { Computer } \\
\text { Sciences }\end{array}$ & 0.79 & Geosciences & 0.34 & $\begin{array}{l}\text { Computer } \\
\text { Sciences }\end{array}$ & 0.15 \\
\hline Pharmacy & 1.29 & Physics & 0.76 & $\begin{array}{c}\text { Plant \& } \\
\text { Animal } \\
\text { Sciences }\end{array}$ & 0.32 & Physics & 0.14 \\
\hline Neurosciences & 1.25 & Medicine & 0.60 & Mathematics & 0.31 & Microbiology & 0.13 \\
\hline All fields & 1.70 & All fields & 0.87 & All fields & 0.36 & All fields & 0.17 \\
\hline
\end{tabular}

Source: Thomson Reuters Web of Knowledge, Feb 2011

output of these articles in Iran illustrate that engineering field contributed 1.71 percent; chemistry research, 1.68 percent; material sciences and agriculture, 1.19 percent; mathematics, 1.16 percent; pharmacy, 1.05 percent; the plant \& animal sciences, computer sciences, physics and medicine accounted for 3.08 percent of the total: 0.93 percent for plant \& animal sciences, 0.79 percent for computer sciences, 0.76 percent for physics and 0.60 percent for medicine. 0.87 percent of the articles were classified as the other fields. In Turkey, the large number of articles published is related to agriculture field with the global share of 2.87 percent. The engineering field in Turkey ranked third with the global share of 2.22 percent that is more than the global share of engineering in Iran. The global share of research output at the other fields (doesn't name in the table) is considered at the end row of the table, the most and also the least amount of global share in the other fields is related to Turkey and Saudi Arabia.

As a total result, the selected countries are still growing at a slower (Egypt, Saudi Arabia and Israel) and faster (Iran) pace, though from a low base in paper productions. The shares of some research outputs at these nations are low. Turkey and Iran has a better impact performance in comparison to the other nations and also have very high growth rates when compared to the others. The rational and interesting point is that every region prefers to conduct research in special fields, for example, the present paper indicates that the field of engineering act strong in Middle East. Therefore, another region acts in their special fields. 


\section{Conclusion}

This article indicated the scientific condition of the countries in Middle East. Turkey and Iran swelled the output of scientific research more than the other countries in the region during 2000-2009; Iran has demonstrated a remarkable growth in the last five years. According to the Royal Society, Iran has the world's fastest growth rate in scientific output. Thus if this trend continue, it may soon be among the first 10 countries in the World. Most of the Iran's growth has been in engineering and chemistry producing 3.39 percent of the world's total output in 2009. Furthermore, the science portfolio of some countries such as Turkey, Egypt and Saudi Arabia demonstrate that the best performance of Turkey is agriculture; in Egypt is pharmacy; and in Saudi Arabia is mathematics. For all of these reasons, Iran's scientific knowledge is good in Middle East and in the world; but the more scientific research in Iran and Middle East can remove the scientific output gap between Middle East and developed countries.

As recommendations, the incentives can promote more researchers and so more research especially in locally owned enterprises. Solving the fiscal problem of the researches, having the professional manner in doing the research, increasing the staff's knowledge at the universities and institutes can play an important role in improving scientific communications and also the culture of researching. The research beneficiaries of every country demonstrate by the substantial amount of science, so the government can have key role in encouraging, supporting and development the priorities of the research by funding.

\section{References}

Bilsel, A. \& Oral, Ö. (1995). Role of Education, Science and Technology in Developing countries. Gazimagasa: North Cyprus.

Dickson, D. (2004). Scientific output: the real knowledge divides. SciDev Net.

Hugo, H. \& Francisco, V. (2007). Comparing EU and US Scientific Output by Scientific Field. Technological forecasting and social change, 74(8), 1334-1356.

Jafari, S. A. (2006). Examining the Scientific Output in Islamic Countries with Emphasize on Iran. A series of articles at national congress of Islamic Republic of Iran's long term prospective through 1404. Educational and surveying institute of Management and planning, Tehran.

Jafari, S. A. (2007). The Trend of Scientific Output at Different Field among Iranian Scientists in International Valid Press (2004-2007). Scientific output congress-Ministry of sciences, researchers and technology, Tehran.

King, D. A. (2004). The Scientific impact of Nations: What different Countries get for their research spending? Nature, 430, 310-316.

Moin, M. Mahmoudi, M. \& Rezaei, N. (2007). The Scientific Output of Iran from 1970 to 2002. Hakim Press, 10, 8-14.

Purkayatha, P. (2004). Scientific Capability and The wealth of Nations. Communist party of India (Marxist), 28 (50).

Segal, A. (1996). Why Does the Muslim World Lag in Science? Middle East Quarterly, 3 (2), 61-70.

Schnitzer, S. A. \& Holmgren, M. (2004). Science on the Rise in Developing Countries. PLoS Biol 2(1), el. doi: 10.1371/journal.pbio. 0020001.

Zolfi, G. M. A. \& Kiani, B. A. (2007). Scientific Output instances: Select Indexes and Indexes Select. Persian articles bank. (Refer to: http://www.qudsdaily.com/archive/2008/html).

Wagner, C. Brahmakulam, I. Jackson, B. Wong, A. \& Yoda, T. (2001). Science and Technology Collaboration: Building Capacity in Developing Countries? Washington, RAND Science and Technology, 102. 